\title{
CAMINHOS CRÍTICOS NO PROCESSO ENSINO-PRENDIZAGEM EM FILOSOFIA
}

\author{
Critical Ways in the Teaching-Learning \\ Process of Philosophy
}

Márcio Antônio Cardoso Lima1

\section{Resumo}

O autor do texto faz apresentação de pesquisa realizada nos anos 2002/2005, em resposta à inquirição: Quais são as principais filosofias críticas que permeiam o processo ensino-aprendizagem com o ensino de Filosofia? Explicitando-as, opta pela sistematização de dois caminhos críticos: o ensino de Filosofia, que tem como eixo epistemológico a teoria como guia da ação prática, e o ensino de Filosofia como criação de conceitos.

Palavras-chave: Ensino de filosofia; Filosofias críticas; Teoria como guia da ação prática.

\section{Abstract}

The author presents a research carried out in the years 2002/2005, in response to his investigation: What are the main critical philosophies that permeates the teaching-learning process of philosophy? While explaining them, he opts for the systematization of two critical ways: A teaching of philosophy having, as epistemologic axis, theory as a guide for practical action and the teaching of philosophy as a creation of concepts in refutation of both of them through his critical experience referring to the teaching that has been developed since the second half of the 1980's towards the defense of theory as expression of practical action.

Keywords: The teaching of philosophy; Critical philosophies; Theory as a guide of practical action.

Doutor em Educação pela Faculdade de Educação da Universidade Federal de Minas Gerais, professor adjunto do curso de Pedagogia do Câmpus de Miracema do Tocantins/Universidade Federal do Tocantins - UFT. e-mail: marcioacl@uft.edu.br 


\section{Introdução}

Por meio das leituras sobre o ensino da Filosofia em teses e dissertações produzidas no final dos anos 1980 até a primeira metade do ano 2001 - dados da Capes -, livros paradidáticos, compilações de cinco simpósios sul-brasileiros e dois simpósios da região sudeste, pus-me a seguinte problemática: Quais são as principais filosofias críticas que permeiam o processo ensinoaprendizagem com o ensino de Filosofia? O presente texto objetiva, assim, a apresentação desses encaminhamentos críticos para o ensino de Filosofia em resposta à inquirição posta.

O primeiro posicionamento crítico decorre da defesa de que o ensino de Filosofia deve ter como pressuposto básico o aprender a pensar, "entendido não como capacitação lógica, como domínio do uso de um instrumento que ordena o pensamento, como o desenvolvimento da capacidade de questionar, de rejeitar como dado inequívoco a evidência imediata" (SOUZA, 1992, p. 91). O segundo apropria-se do espírito kantiano com ênfase num ensino que privilegie a história da Filosofia: "embora Kant não estivesse muito preso à história da filosofia, as suas considerações a respeito da Filosofia e do exercício da razão acabam confirmando a pertinência da história da filosofia no ensino da Filosofia", tendo em vista "o exercício do pensamento, [...] a sua emancipação" (GUIDO, 2000, p. 84-90).

O terceiro caminho tem como referencial teórico-metodológico o pensamento gramsciano - Cartolano (1985); Silveira (1991) e Alves (2002) em objetivação à superação do senso comum para poder forjar nova consciência, crítica e consciente, também fundamentado na história da Filosofia, já que "não se pode separar a Filosofia da história da Filosofia" (GRAMSCI, 1989, p. 13).

Por fim, a quarta proposta, bastante polêmica, no campo da criticidade, refere-se à definição da Filosofia como "disciplina que consiste em criar conceitos" (DELEUZE; GUATTARI, 1992, p. 13) e sua transposição para o ensino da Filosofia. Para o propugnador desse encaminhamento, "não se ensina Filosofia impunemente; não se aprende Filosofia impunemente. A 'oficina de conceitos' é um local perigoso, de onde podem trocar conceitos que sejam ferramentas para mudar o mundo" (GALLO, 2002, p. 208). Portanto, essa vertente propõe um ensino de Filosofia como possibilidade de criação (de conceitos), e tal criação seria uma intervenção no mundo, ou melhor, a criação de conceitos é a própria criação de um mundo.

Em vista da explicitação desses caminhos críticos, sistematizarei as posições de Silveira (1991) e Gallo (1999), à luz das seguintes razões: (i) Silveira (1991) é pioneiro na ordenação de proposta crítica de Filosofia, isto é, a teoria como guia da ação prática, em espaço de tempo determinado da 
Caminhos críticos no processo ensino-aprendizagem em filosofia

história da educação brasileira, isto é, o final da segunda metade dos anos 1980 e começo dos anos 1990 e, (ii) Gallo (1999) é pioneiro na suspeição da perspectiva crítica de Silveira e a defesa do ensino de Filosofia como criação de conceitos, em espaço de tempo determinado na história da educação brasileira, isto é, o final dos anos 1990, estendendo-se aos anos iniciais desse novo século.

\section{O trabalho de Silveira (1991): por um "um ensino revolucionário de Filosofia"}

Exporei o trabalho de Silveira (1991) por um ensino de Filosofia crítico. Inicialmente, no capítulo IV de sua dissertação, "Discutindo o papel da filosofia no ensino de $2^{\circ}$ grau", apropria-se do filósofo marxista Schaff para expor a sua posição quanto ao 1 Problema do conhecimento e da verdade (SILVEIRA, 1991, p. 422-435).

De acordo com Schaff, para responder à problematização sobre a questão do conhecimento e da verdade, três modelos são significativos: o modelo objetivo-mecanicista, o modelo idealista-ativista e o modelo objetivoativista. Silveira (1991, p. 423) toma partido do último, porque nele há interação recíproca: "O sujeito conserva seu papel ativo, mas, ao mesmo tempo, sofre a influência de inúmeras determinações, sobretudo sociais, que interferem na forma como capta o objeto".

Em seguida, 2 Uma definição de Filosofia (SILVEIRA, 1991, p. 436453), considerada como uma atitude de busca do saber, do conhecimento, isto é, a busca da verdade. E, apoiando-se no filósofo marxista Gramsci, entende que isso se dá na passagem do senso comum à consciência filosófica. Porém, uma observação: se a Filosofia está em busca da verdade, ela não é a única área do conhecimento que o faz, já que a ciência também tem essa preocupação.

Qual é, então, a especificidade da Filosofia? Resposta: "Creio ser possível afirmar, sem grandes problemas, que a filosofia é, fundamentalmente, um trabalho de reflexão" (SILVEIRA, 2000, p. 131). Nesse instante, cita autor conhecido: "A filosofia não se caracteriza por um conteúdo específico, mas ela é, fundamentalmente, uma atitude; uma atitude que o homem toma perante a realidade. Ao desafio da realidade, representado pelo problema, o homem responde com a reflexão" [grifo meu] (SAVIANI, 1984, p. 23).

Porém, não é qualquer reflexão, para ser filosófica, a reflexão tem de cumprir três exigências: ela precisa ser radical, isto é, ir às raízes do problema, investigá-la em profundidade; ela precisa ser rigorosa, isto é, sistemática, com base em procedimentos metodológicos bem definidos; ela precisa ser de conjunto, isto é, o problema deve ser encarado não isoladamente, mas numa perspectiva de totalidade (SAVIANI, 1984, p. 24). 
Em seguida, passa ao primeiro tópico do segundo subtítulo: $\mathbf{2 . 1} \mathbf{0}$ sujeito da reflexão filosófica (SILVEIRA, 1991, p. 439-446). Para o pesquisador, a reflexão radical, rigorosa e de conjunto precisa estar conectada ao homem concreto, objetivo, considerado "como conjunto de relações sociais" e "síntese de múltiplas determinações"; um homem em interação com os outros homens e com a natureza (GRAMSCI, 1989, p. 39); que modifica a si mesmo e o conjunto de suas relações (GRAMSCI, 1989, p. 40-48).

Eis que diante dessa posição, várias perguntas surgem: "quem (quantos) são esses sujeitos? Apenas os mais 'cultos'? Ou se poderia afirmar que todos os homens são filósofos? E em que sentido o seriam?" (SILVEIRA, 1991, p. 440). Primeiramente, retoma Gramsci (1989, p. 11) para apagar a idéia de que a Filosofia seja algo complexo, restrita a alguns iluminados, já que para ele "todos os homens são "filósofos".

Após isso, procura explicar o sentido dessa proposição: todos os homens são capazes de pensar e de conhecer, já que expressam concepção de mundo na vida cotidiana, dentro de limites do senso comum, de uma filosofia espontânea, de um conhecimento assistemático, difuso, acrítico, ingênuo. Todavia, é imprescindível dar um salto e, aí, fazer Filosofia, "pois o objetivo da reflexão filosófica em relação ao senso comum deve ser o da superação" (SILVEIRA, 1991, p. 444).

Para que isso ocorra, isto é, para fazer do ensino de Filosofia um meio de superação do senso comum, para torná-lo uma reflexão radical, rigorosa e de conjunto, é importante a apropriação do saber sistematizado ao longo da história, isto é, da história da Filosofia, como de instrumentalização das massas (SILVEIRA, 1991, p. 445) para a transformação da sociedade.

Depois de definido o sujeito da reflexão filosófica, passa ao tópico seguinte: 2.20 objeto da filosofia (SILVEIRA, 1991, p. 447-451), retomando Saviani (1984), para quem o homem é levado a refletir, isto é, a filosofar, quando é interrompido por algo a que se dá o nome de problema, no transcorrer natural de sua existência. Cito-o: "O ponto de partida da filosofia é, pois, esse algo a que damos o nome de problema. Eis, pois, o objeto da filosofia, aquilo que trata a filosofia, aquilo que leva o homem a filosofar: são os problemas que o homem enfrenta no transcurso de sua existência" (SAVIANI, 1984, p. 17).

Todavia, é importante definir o que se entende por problema: não é sinônimo de questão, não se refere a algo que não se sabe, a um mistério ou enigma; é dado como uma necessidade objetivo-subjetiva que precisa ser desvelada, superada (SAVIANI, 1984, p. 18-23), à luz de uma reflexão radical, rigorosa e de conjunto.

Depois dessa exposição, Silveira (1991, p. 451-543) passa ao último tópico do segundo subtítulo: $\mathbf{2 . 3} 0$ caráter revolucionário da filosofia. Após 
as posições anteriores, uma interrogação: Com qual classe social a Filosofia está comprometida? Noutro texto, isso fica bastante claro: "Numa formação social baseada na exploração de uma classe sobre a outra e que se mantém, em parte, pela dissimulação dessa exploração, a explicitação da verdade só pode mesmo interessar à classe explorada, pois é condição para sua libertação." (SILVEIRA, 2000, p. 135).

Explicita-se, assim, para Silveira (2000), o caráter revolucionário da Filosofia, pois o trabalho com o ensino de Filosofia a favor dos explorados possibilitará esclarecer as contradições presentes em uma sociedade de classes, visando a sua superação, visto que emergirá a consciência crítica.

Em decorrência disso, o último subtítulo 3 Aspectos de um ensino revolucionário de filosofia. Inicialmente, Silveira (1991, p. 453-493) faz algumas advertências: a primeira refere-se à impossibilidade duma Filosofia aceita universalmente não somente porque tem definições diferentes, mas também porque está comprometida com os interesses dominados; porém, ela não é, também, a única concepção revolucionária a serviço desses interesses.

A segunda é que as considerações da realização do ensino de Filosofia, que se seguirão, não devem ser adotadas dogmaticamente; e a última refere-se à expressão "ensino revolucionário de Filosofia": o autor está ciente de que a mera inclusão de Filosofia, ainda que trabalhada da forma como ele a entende, não possibilitaria, em si mesma, uma transformação revolucionária da sociedade, porém pode agir sobre os sujeitos da prática social, em prol da transformação social.

Após essas advertências, passa aos enfoques duma prática revolucionária de ensino de Filosofia baseada em quatro aspectos: os objetivos, os conteúdos, a metodologia e a avaliação. No primeiro 3.1 Quanto aos objetivos (SILVEIRA, 1991, p. 457-458), um alerta: o ensino de Filosofia não visa a doutrinação, "mas a instrumentalização [grifo do autor] teórico-prática dos estudantes" (SILVEIRA, 1991, p. 457), a partir da apropriação crítica de certos conceitos e teorias ao longo da história da Filosofia para melhor compreensão da realidade em que vivemos.

E, para fortalecer essa prática pedagógica de cunho revolucionário, apropria-se de Saviani (1983, p. 74-75):

Trata-se de se apropriar dos instrumentos teóricos e práticos necessários ao equacionamento dos problemas detectados na prática social. [...] Trata-se da apropriação pelas camadas populares das ferramentas culturais necessárias à luta social que travam diuturnamente para se libertar das condições de exploração em que vivem.

Após os objetivos, o outro tópico do terceiro subtítulo: 3.2 Quanto ao conteúdo programático (SILVEIRA, 1991, p. 459-470). Retoma Saviani 
(1984), ao afirmar que conteúdo programático deve estar concatenado como instrumento para o enfrentamento dos problemas que os alunos enfrentam em sua existência concreta:

Um programa de Filosofia, para que possa ser caracterizado como tal, e para que venha cumprir uma função revolucionária, deve selecionar conteúdos significativos que, uma vez apropriados pelos educandos, contribuam para instrumentalizá-los teórica e praticamente, de modo a melhor capacitá-los para uma apreensão crítica das relações sociais que vivenciam e para um engajamento consciente visando a sua transformação. (SILVEIRA, 1991, p. 462-463).

E, para que isso ocorra, é preciso fazer uso da história da Filosofia, na qual se encontram elementos que possam colaborar nessa instrumentalizacão, principalmente para a compreensão e enfrentamento dos problemas da atualidade. Contudo, os problemas e a seleção dos conteúdos, por serem desenvolvidos em sala, ficam sob a inteira responsabilidade do professor, já que "ele possui uma compreensão mais elaborada e global da prática social."[...]. Ele pode e deve ouvir os alunos, sim, mas "se restringir aos aspectos levantados pelos alunos, muito provavelmente a reflexão não sairá do plano superficial das opiniões, do senso comum." (SILVEIRA, 1991, p. 469-470).

Para efetivar essa instrumentalização, outro aspecto é importante: $\mathbf{3 . 3}$

Quanto à metodologia (SILVEIRA, 1991, p. 470-493). Por metodologia compreende-se basicamente o apoio da história da Filosofia como referencial obrigatório para lidar com o ensino de Filosofia, incentivando o prazer da reflexão radical, rigorosa e de conjunto, aos interesses dos dominados.

Entretanto, para que isso ocorra, é importante o bom uso dos recursos didáticos. O primeiro uso de recursos didáticos é (i) Bibliografia (SILVEIRA, 1991, p. 477-480): a adoção de livros didáticos; a utilização de textos esparsos extraídos de diversas fontes e a confecção dos textos pelo próprio professor. Tais recursos não são excludentes, por isso podem ocorrer combinações das três possibilidades. O segundo uso de recursos didáticos, (ii) Dinâmicas de Grupo (SILVEIRA, 1991, p. 481-482), consiste no desenvolvimento do espírito de solidariedade e cooperação, na distribuição das tarefas, condições para o exercício da criatividade, etc. Porém, certo cuidado para que a dinâmica de grupo "não se transforme em instrumento de dissimulação da realidade" (SILVEIRA, 1991, p. 482).

O penúltimo uso de recursos didáticos, (iii) Recursos audiovisuais (SILVEIRA, 1991, p. 482- 483) remete ao uso de slides, retroprojetor, episcópio, videocassete e outros, para enriquecimento dos conteúdos tratados. Porém, se não houver devido cuidado, tais recursos poderão ser empecilhos para o cumprimento de uma reflexão crítica. E, por último, (iv) Recursos artísticos 
e literários (SILVEIRA, 1991, p. 483-489), como a música, o teatro, a poesia, o cinema, a literatura em geral, histórias em quadrinhos.

E, novamente, uma advertência: o uso desses recursos, não ocorre aleatoriamente, mas sim com o objetivo de fazer com que "as aulas de filosofia consigam 'seduzir' os alunos e despertar-lhes o gosto, o prazer pela reflexão, pela busca da verdade, pela crítica, consigam motivá-los a prosseguir com a prática da reflexão mesmo após o término do processo pedagógico" (SILVEIRA, 1991, p. 487).

A avaliação, 3.4 Quanto à avaliação (SILVEIRA, 1991, p. 489493), tem como objetivo verificar se os alunos estão sendo capazes de reflexão radical, rigorosa e de conjunto, de reflexão que, por meio de provas, dissertações, debates, dinâmicas de grupo, trabalhos monográficos, pesquisas e outros, vá além do senso comum. Se houver a auto-avaliação, esta deve estar combinada com outros critérios de avaliação.

No que se refere aos aspectos de um ensino revolucionário de Filosofia, Silveira (1991, p. 492-493) conclui o seu trabalho com o que se segue:

Estes me parecem ser alguns dos aspectos que poderiam caracterizar um ensino de Filosofia comprometido com os interesses dos dominados. Obviamente, este ensino não se reduz ao preenchimento meramente formal de itens de um planejamento, tão a gosto do tecnicismo. A opção por caracterizá-lo de acordo com os tópicos 'objetivos', 'conteúdo', 'metodologia' e 'avaliação' deu-se apenas para efeito de facilitar a exposição. A bem da verdade, é na concretude do processo pedagógico, repleto de contradições, dificuldades e esperanças, que o ensino de Filosofia pode revelar toda sua riqueza e fecundidade.

Admito que essa proposta para o ensino de Filosofia é bastante criticada nos dias atuais. Apropriar-me-ei, a princípio, de um teórico pós-moderno contrário ao marxismo, o qual afirma que esse encaminhamento é parte da tradição moderna ocidental que, embasada teoricamente nos contornos iluministas de busca de autonomia, por meio da ciência e da técnica, "depositou uma expectativa muito elevada de trabalho nos ombros frágeis do pedagogo-professor, e da própria Pedagogia" (TREVISAN, 2004, p. 11).

O argumento dos corifeus dessa tradição moderna ocidental, especialmente os marxistas, reside na crença de que a mera transposição dessa tradição para o ensino, mediante a transmissão de conteúdos, engendraria a formação de um sujeito crítico, racional e emancipador, capaz, portanto, de luta pela construção de uma sociedade justa e socialista: 
Desde o momento em que o professor inicia a sua aula ensinando ciência, história ou qualquer outra disciplina, pode não estar se dando conta, mas age como se houvesse um pano-de-fundo consensual em sua prática, no sentido de que o conteúdo ensinado estaria contribuindo para fazer a humanidade progredir em direção a dias melhores. Mesmo os currículos dos diferentes níveis de ensino são organizados em função de etapas progressivas de desenvolvimento e aprendizado. (TREVISAN, 2004, p. 17).

Entretanto, para Trevisan (2004, p. 18-19), chegou a hora de combater essa retórica progressista e ilusionista, em defesa duma perspectiva deflacionista da verdade, minimizando os problemas docentes, simplificando-os, em "valorização do transitório, do aqui e agora, enfatizando não mais a busca de princípios sólidos e estáveis de conduta a seguir, mas a vivência dos aspectos de conduta ligados à leveza, ao efêmero, à sensibilidade, à feminilidade, à cultura da imagem e da estética."

Assim, para ele, a defesa desse novo paradigma decretará "a quebra das hierarquias epistemológicas, [...] [pois] todos os campos do saber são convocados a dialogar com o mundo da vida, com a realidade que os cerca, $[. .$.$] com o contexto de onde tudo parte e ao qual tudo$ retorna" [...]. E, para concluir, afirma que nessa mudança, "o centro de gravidade não é mais o saber metafísico ou epistemológico do saber [...], e sim a linguagem, a comunicação e a relação intersubjetiva entre atores do discurso" (TREVISAN, 2004, p. 19).

Considero, todavia, que suas críticas são endereçadas a determinado tipo de marxismo que se tornou hegemônico no mundo acadêmico, isto é, o marxismo das forças produtivas ou marxismo ortodoxo, no total desconhecimento do marxismo das relações de produção ou marxismo heterodoxo. Portanto, há duas correntes distintas e antagônicas na obra de Karl Marx, que "se articulam contraditoriamente numa doutrina unificada" (BERNARDO, 1991, p. 310), porém, com "o desenvolvimento histórico [...] romperia aquele campo comum, levando à divergência de suas práticas e impossibilitando que fossem pensadas num sistema unificado" (BERNARDO, 1991, p. 310).

Diante disso, é importante o entendimento dos caminhos postos por esse estudioso, a percepção do caráter contraditório do conjunto da obra de Karl Marx. O primeiro, o marxismo ortodoxo, tem como sustentação o marxismo das forças produtivas: 
Desenvolve as teses em que Marx conferia ao mercado o lugar privilegiado na definição do capitalismo, considerando que só nesse nível o produto adquiria um caráter social. [...] Seriam elas (as forças produtivas) a base da ruptura e da transformação. Marx teve, para tal, de neutralizar a tecnologia, tanto a gestão e a organização do trabalho como a maquinaria, torná-la independente das determinações do capitalismo, de maneira a fazê-la sustentar um modo de produção oposto àquele em que começara a sua existência [...]. (BERNARDO, 1991, p. 310-311).

Para tal enfoque, os elementos de transformação, isto é, as forças produtivas, embora integrantes do capitalismo, fundamentam sua superação e contêm, em germe, as características do futuro modo de produção. Dá-se, assim, apropriação de posições teóricas dogmáticas do pensamento de Marx, assumidas por militantes e teóricos, como "ditadura do proletariado", "formas de transformação do modo de produção capitalista em outro modo de produção".

O segundo, o marxismo heterodoxo, tem como sustentação as relações sociais. É o que enfatiza Bernardo (1991, p. 314) ao afirmar:

Marx atribui à mais-valia o lugar central e, portanto, concebe o modo de produção, acima de tudo, como um modo de exploração, definindo-se como seu fundamento dadas relações sociais. São então as relações sociais que explicam as forças produtivas, às quais seria logicamente impossível atribuir, neste contexto, qualquer neutralidade ou autonomia de desenvolvimento. Desempenhando as relações sociais de produção um papel de tal modo global e determinante, só no seu nível poderá ser analisada a problemática da passagem ao modo de produção seguinte. O que significa que, como as relações de produção se estruturam pela mais-valia e são, portanto, contraditórias, é no nível das lutas sociais que tal problemática deverá ser analisada.

Esse posicionamento alicerçado nas lutas sociais tem os trabalhadores como o sujeito coletivo da transformação do modo de produção capitalista. Tais lutas propiciam relações sociais coletivas, solidárias e antagônicas às relações individualistas e competitivas do capitalismo.

Depois dessa exposição, passo à segunda crítica do construto marxista para o ensino de Filosofia advinda de um sociólogo marxista, porém, heterodoxo (SANTOS, 1992). Com base nesse teórico, há em Silveira (1991) uma proposta de base marxista ortodoxa para o ensino de Filosofia, com um forte componente ideológico, uma vez que o saber escolar restringe-se ao campo da distribuição dos bens educacionais, isto é, a mercadoria "saber" pelo desnudamento dos seus elementos negativos (SANTOS, 1992, p. 25-26) é posta à disposição dos alunos para sua operacionalização teórico-prática. Isto é: a transmissãoassimilação de conteúdos, pelo estímulo à consciência crítica, antecipa 
deterministicamente por meio do pensamento, do cognitivo, do racional, os resultados da ação. Assim, a defesa dentro do campo epistemológico de que a prática decorre da teoria, ou melhor, a concepção da teoria como guia da ação prática.

Indicarei algumas citações que corroboram o que foi delineado no último parágrafo, a começar pelo próprio Silveira (1991, p. 457):

Um ensino assim compreendido deve ter como objetivo primordial a instrumentalização [grifo do autor] teórico-prática dos estudantes, de modo a capacitá-los para uma compreensão mais fundamentada e global da realidade em que vivem e, ao mesmo tempo, para uma tomada de posição consciente e crítica em face dessa realidade. [...]. No caso específico do ensino de filosofia, essa instrumentalização teórico-prática implica na aquisição e do domínio crítico pelos alunos de certos conceitos e teorias que fazem parte do conjunto de questões e reflexões que compõem a história da filosofia e que se revelam indispensáveis para a compreensão da realidade atual.

Noutro livro, Silveira (2003, p. 43) continua na defesa dessa postura para o ensino em geral, especificamente para o ensino de Filosofia:

A função específica da educação escolar [...] consiste na socialização do saber historicamente acumulado pela humanidade e sistematizado nas diversas disciplinas do currículo, incluindo, evidentemente, a filosofia. Cabe à escola garantir que os alunos se apropriem desse saber, a fim de alcançarem um patamar mais elaborado de compreensão da realidade que os torne mais bem preparados para intervir de forma consciente e crítica nessa realidade. Isso é particularmente importante para os alunos oriundos das camadas populares que, via de regra, têm na escola a principal, senão a única, fonte de acesso a esse saber, sem o qual ficariam em condição ainda mais desfavorável na sociedade, em que já são discriminados e excluídos.

Em segundo lugar, cito Gramsci (1989, p. 13-14), um dos teóricos no campo da Filosofia que Silveira (1991) se apropria para subsidiar o olhar sobre o ensino:

Criar uma nova cultura não significa apenas fazer individualmente descobertas "originais"; significa também, e sobretudo, difundir criticamente verdades já descobertas [grifo meu], "socializá-las" por assim dizer; transformá-las, portanto, em base de ações vitais, em elemento de coordenação e de ordem intelectual e moral. O fato de que uma multidão seja conduzida a pensar coerentemente e de maneira unitária a realidade presente é um fato "filosófico" bem mais importante e "original" do que a descoberta, por parte de um "gênio filosófico", de uma nova verdade que permaneça como patrimônio de pequenos grupos intelectuais. 
Penso que esse componente ideológico conforme aludido por Santos (1992), o saber se restringindo ao campo da distribuição dos bens educacionais, se presentifica na proposta pedagógica de Silveira (1991): ele faz uma arrumação didática de como deve ser o ensino de Filosofia para os que são professores e/ ou para futuros professores de Filosofia. Parte, primeiro, da inteligibilidade do problema do conhecimento e da verdade; em seguida, da sua definição de Filosofia e, finalmente, dos aspectos de um ensino revolucionário de Filosofia. Portanto, nos fornece um receituário para o saber filosófico a serviço dos trabalhadores.

Entretanto, não há nenhum interesse por parte de Silveira (1991) em saber de antemão da experiência prática dos trabalhadores, além da especificação da conjuntura histórica. Esse atroz esquecimento vai ao encontro da evidência de que é no campo das lutas sociais, marcadamente contraditório, que são gerados os processos pedagógicos. Por isso, não existem receitas prontas para a viabilização do ensino; é preciso valorizar a prática de quem penetra no interior do espaço escolar e os problemas que são postos por ela. Daí um novo construto epistemológico para lidar com o ensino: a teoria como expressão da prática.

\section{A posição de Gallo (1999) para o ensino de filosofia: "a filosofia tem uma ação criadora (de conceitos) e não é mera passividade frente ao mundo"}

Exporei, nesse instante a posição de Gallo (1999) para o ensino de Filosofia. Na Introdução, Gallo (1999, p. 1) afirma que seu propósito consiste na aplicação da filosofia de Deleuze em colaboração com Guattari à Filosofia da Educação, ou melhor, roubará conceitos daquele, recriando-os, "para pensarmos o sentido e a tarefa da filosofia da educação em nossos dias".

No primeiro subtítulo do seu trabalho, intitulado "Deleuze, filósofo da multiplicidade", procura indicar a importância desse teórico no estudo de importantes figuras no campo filosófico (Hume, Bergson, Spinoza, Leibniz, Kant, Nietzsche) para a construção de novos mapas conceituais, retratando, assim, o seu papel de historiador da Filosofia, ou melhor, tais encontros propiciam o roubo, roubo de conceitos, recriando-os e ensejando nessa filosofia o desvio.

Porém, outros encontros são também importantes: o encontro com o cinema, com a literatura (Kakfa, Beckett, Jarry, Sacer-Masoch, Lawrence, a literatura americana), com a Psicanálise, com Félix Guattari, colaborador em várias obras, entre elas O que é filosofia? (DELEUZE; GUATTARI, 1992). 
No subtítulo seguinte, "Rasgar o caos: a filosofia como criação de conceitos", o autor expõe o entendimento de Deleuze sobre o que é Filosofia, já presente nas primeiras páginas: "a filosofia é arte de formar, de inventar, de fabricar conceitos" (DELEUZE; GUATTARI, 1992, p. 10). Para o autor do texto, tais teóricos dão um golpe certeiro: "a filosofia tem uma ação criadora (de conceitos), e não é uma mera passividade frente ao mundo" (GALLO, 1999, p. 4). Portanto, discordância duma das Teses contra Feuerbach, de Marx, pois, ao criar conceitos, há intervenção no mundo, já que é a própria criação de um mundo.

Todavia, não é somente isso já que a filosofia não pode ser vista como contemplação, como reflexão, como comunicação. Ela não é contemplação, já que a contemplação visa a coisa mesma, portanto "nada tem a ver com a criação de conceitos" (GALLO, 1999, p. 5); não é comunicação, já que a comunicação tem um olhar sobre o consenso, "e o conceito, muitas vezes, é mais dissenso que consenso" (Idem, p. 5); também não é reflexão, já que a reflexão não é específica do fazer filosófico, pois "os matemáticos como tais não esperaram jamais os filósofos para refletir sobre a matemática, nem os artistas sobre a pintura ou a música; dizer que eles se tornam então filósofos é uma brincadeira de mau gosto, já que sua reflexão pertence à sua criação respectiva" (DELEUZE; GUATTARI, 1992, p. 14).

Diante disso, uma pergunta de cunho filosófico: o que é um conceito? É chegada a hora dessa inquirição, visto que raras vezes na história da Filosofia houve um esforço para responder à indagação. Para tais autores, o conceito é uma aventura do pensamento para instituição de um acontecimento, intentandose, assim, ressignificar o mundo.

Todavia, para melhor compreensão, ele tem as seguintes características: o conceito é assinado, na medida em que cada filósofo "assina o mundo à sua maneira, através dos conceitos que cria" (GALLO, 1999, p. 6). Não há conceito simples, o conceito é uma multiplicidade; o conceito é criado em razão de problemas, não é criado do nada, há um solo: plano de imanência; ele é uma heterogênese, "é que cada componente distinto apresenta um recobrimento parcial, uma zona de vizinhança” (DELEUZE; GUATTARI, 1992, p. 31).

Todo conceito é um incorporal, nunca é a coisa-mesma, é sempre um acontecimento; ele é simultaneamente absoluto e relativo: absoluto em relação a si mesmo, relativo em relação ao seu contexto (GALLO, 1999, p. 8); enfim, o conceito não é discursivo, não é proposicional: "essa é uma singularidade da ciência, que permite que ela seja reflexiva e comunicativa, mas não da filosofia" (GALLO, 1999, p. 8).

Porém, essa multiplicidade de elementos que compõem o conceito se dá por meio do plano de imanência, isto é, o solo e o horizonte da produção conceitual; além da personagem conceitual que completa a definição da Filosofia 
como criação de conceitos. Temos, então, três instâncias correlacionais da Filosofia: "o plano de imanência que ela precisa traçar, os personagens que ela precisa inventar e os conceitos que deve criar" (GALLO, 1999, p. 10). Noutras palavras, os verbos traçar, inventar e criar são constituintes do fazer filosófico, e não os verbos contemplar, refletir e comunicar.

Ao findar essa exposição, o autor passa ao último subtítulo, "Filosofia e Educação: um encontro possível". Uma pergunta inicia o tópico: Que teria Deleuze a dizer à Educação como campo de produção de saberes?, que se traduz em: Que é possível de ser dito sobre Educação, de acordo com Deleuze?

Em primeiro lugar, Gallo (1999) critica a tradição da Filosofia da Educação no Brasil, que defende que o ensino de Filosofia da Educação deve se pautar pela reflexão sobre os problemas educacionais por meio de uma reflexão radical, rigorosa e totalizante. Para o autor do texto, baseando-se em Deleuze, eis uma posição empobrecedora e reducionista, pois retira dela (a Filosofia) a sua capacidade de criação. Mediante isso, faz-se importante o combate aos que vêem na Filosofia da Educação a reflexão sobre a educação.

Um segundo combate refere-se aos que situam a Filosofia da Educação como um dos fundamentos da educação. Assim, dá a ela a capacidade de fornecer as bases para o processo educativo e fornece os conceitos produzidos ao longo da história, ou um resgate daquilo que os filósofos pensaram sobre a educação. Eis que novamente raspam-se ossos como cães famintos, tornando a Filosofia da Educação desinteressada e despotencializada.

É importante, então, a busca de nova Filosofia da Educação, "pondonos a serviço da boa Filosofia e da boa educação" (GALLO, 1999, p. 14). Onde encontrá-la? Evidentemente, na filosofia deleuziana e, para confirmação, uma citação: "Parece-me que a inspiração deleuziana é bastante interessante. O filósofo da educação deve ser um criador de conceitos. Mas o que o diferencia dos demais filósofos? Absolutamente nada, a não ser seu mergulho no território da Educação, que nem todo filósofo pode ou deseja fazer" (GALLO, 1999, p. 14).

Depois dessa exposição, uma pequena consideração: Gallo (1999), ao combater ferrenhamente o caráter hegemônico de determinada posição filosófica - reflexão radical, rigorosa e de conjunto - numa nova perspectiva, agora deleuziana - a filosofia como (re)criação de conceitos - faz isso acreditando que há na posição de Saviani (1984) exacerbada preocupação pedagógica, esquecendo-se, então, da questão filosófica.

Portanto, é necessário dar ao ensino norte filosófico, que somente pode ser encontrado na Filosofia, preferencialmente nos teóricos que vêem a Filosofia como atividade de pensamento, ou melhor, fundamentalmente pensamento conceitual. Isso é bem tratado noutro texto por Gallo; Kohan (2000, p. 190): "A questão do ensino de filosofia é uma questão filosófica e não meramente pedagógica e deve, portanto, ser enfrentada como tal". 
Dito de outra maneira, é categórico que "o sentido do ensino de Filosofia seja tratado como uma 'pedagogia do conceito', que ele seja tratado de forma estritamente filosófica" (GALLO; KOHAN, 2000, p. 191), evitando, assim, tratá-lo exclusivamente no plano pedagógico, pois a "atividade filosófica é em si mesma educativa, não faz sentido falar em ensino de Filosofia no contexto de didática apenas instrumental" (GALLO; KOHAN, 2000, p. 191).

Com base nessa disposição, tratando a Filosofia como atividade de fazer experiências de pensamento, o ensino de Filosofia terá a marca da crítica radical, pois a não-satisfação "com o estado das coisas, age sobre elas produzindo conceitos críticos que são essencialmente transformadores. Assim, a Filosofia parte de um incômodo existencial para tornar-se, ela mesma, um incômodo para a sociedade estabelecida" (GALLO; KOHAN, 2000, p. 193194).

Indico que há, aqui, a elaboração de nova perspectiva acadêmica para o ensino de Filosofia, com base nos pós-estruturalistas franceses Deleuze e Guattari, para o combate de uma percepção acadêmica que se tornou hegemônica, no caso, o marxismo ortodoxo. Urge, portanto, a fundação de nova perspectiva para o ensino de Filosofia que não fizesse nenhuma discriminação em relação à própria Filosofia, ou melhor, a Filosofia como criação de conceitos.

\section{Considerações finais}

O encaminhamento para o ensino crítico não se reduz à defesa de um saber estritamente filosófico, muito menos em trato exclusivamente pedagógico. Ambos os paradigmas para o ensino de Filosofia são atravessados por viés abstrato, sem se darem conta de que o trato com o ensino é questão eminentemente concreta, fruto da prática social, marcadamente contraditória, pois é resultante de conflitos entre as classes sociais:

A verborréia acadêmica que glosa até ao infinito o tema de que as classes já não existem e que os trabalhadores são uma espécie condenada à extinção serve de coro à grande ambição dos capitalistas, a de serem eles os únicos a ocupar o palco e de recusarem aos trabalhadores qualquer lugar no enredo, remetendo-os para os bastidores onde, sujeitos invisíveis, caber-lhes-ia apenas mover os cenários, manipular as luzes, subir e baixar a cortina. Nesta metáfora falta o público, porque na história não existe público, e é isso que mais tarde ou mais cedo obriga os sujeitos invisíveis a tornarem-se atores. (BERNARDO, 2004, p. 16). 
Em ambas as propostas, por conseguinte, o saber filosófico as acompanha: a primeira, isto é, a teoria como guia da ação prática, defende um saber crítico, conquistado conteudisticamente pela história da Filosofia numa orientação didática; a segunda, isto é, a Filosofia como criação de conceitos, acredita que a posse de uma pedagogia dos conceitos, tomando-os filosoficamente, é, em si mesma, um elemento de transformação, em sutil crítica à orientação didática da primeira.

Contrapõem-se, porém, não se distanciam, uma vez que acreditam na força mágica do pensamento como possibilidade de transformação. Em ambas, portanto, há a presença de um caráter abstrato nas propostas: ao passo que na primeira há certa especificação quanto ao atendimento da proposta, um rosto bem delineado; na segunda, há generalização, sem nenhuma destinação do encaminhamento filosófico para o ensino de Filosofia.

\section{Referências}

ALVES, Dalton José. A filosofia no ensino médio: ambigüidades e contradições na LDB. Campinas: Autores Associados, 2002.

BERNARDO, João. Economia dos conflitos sociais. São Paulo: Cortez, 1991.

Democracia totalitária: teoria e prática da empresa soberana. São Paulo: Cortez, 2004.

CARTOLANO, Maria Teresa Penteado. Filosofia no 2o grau. São Paulo: Cortez, 1985.

DELEUZE, Gilles; GUATTARI, Félix. O que é filosofia? Tradução de Bento Prado Jr. e Alberto Alonso Muñoz. Rio de Janeiro: Editora 34, 1992.

GALLO, Sílvio. O que é filosofia da educação? Anotações a partir de Deleuze e Guattari. ANPEd. In: REUNIÃO ANUAL DA ANPEd; 22., 1999, Caxambu. Anais... Caxambu: GT Filosofia da Educação, 1999.

KOHAN, Walter Omar. Crítica de alguns lugares-comuns ao se pensar a filosofia no ensino médio. In: GALLO, Sílvio; KOHAN (Org.). Filosofia no ensino médio. Petrópolis: Vozes, 2000.

A especificidade do ensino de Filosofia: em torno dos conceitos. In: PIOVESAN, Américo et al. Filosofia e ensino em debate. Ijuí: Unijuí, 2002.

GRAMSCI, Antônio. Concepção dialética da história. Tradução de Carlos Nelson Coutinho. 8. ed. Rio de Janeiro: Civilização Brasileira, 1989. 
GUIDO, Humberto A. O. A filosofia no ensino médio: uma disciplina necessária. In: GALLO, Śllvio; KOHAN, Walter Omar (Org.). Filosofia no ensino médio. Petrópolis: Vozes, 2000. p. 81-93.

SANTOS, Oder José dos. A pedagogia dos conflitos sociais. Campinas: Papirus, 1992.

SAVIANI, Dermeval. Escola e democracia: teorias da educação, curvatura da vara e onze teses sobre educação e política. São Paulo: Cortez, 1983.

Educação: do senso comum à consciência filosófica. 4. ed. São Paulo: Cortez, 1984.

SILVEIRA, Renê José Trentin. Ensino de filosofia no segundo grau: em busca de um sentido. 1991. 612 f. Dissertação (Mestrado em Educação) - Universidade Estadual de Campinas, Campinas, 1991.

. Um sentido para o ensino de filosofia no nível médio. In: GALLO, Sílvio; KOHAN, Walter Omar (Org.). Filosofia no ensino médio. Petrópolis: Vozes, 2000. p. 129-148.

Matthew Lipman e a filosofia para crianças: três polêmicas. Campinas: Autores Associados, 2003.

SOUZA, Sônia Maria Ribeiro de. Por que filosofia? uma abordagem históricodidática do ensino de Filosofia no $2^{\circ}$ grau. 1992. 225 f. Tese (Doutorado em Educação) - Universidade de São Paulo, São Paulo, 1992.

TREVISAN, Amarildo Luiz. Terapia de atlas: pedagogia e formação docente na pós-modernidade. Santa Cruz do Sul: EDUNISC, 2004. 